\title{
Ocena wydajności spawania niskoenergetycznego procesu SpeedRoot w pozycji PG
}

\author{
The capacity assessment of low energy \\ SpeedRoot welding process in PG position
}

\section{Streszczenie}

W artykule przedstawiono wyniki badań, poświęconych porównaniu warunków spawania i właściwości technologicznych spawania złączy doczołowych innowacyjną niskoenergetyczną odmianą metody MAG - SpeedRoot w pozycji PG z tradycyjnym spawaniem metodą TIG w pozycji PF. Oceniono wydajność spawania obu procesów, charakterystyki dynamiczne źródeł zasilania oraz geometrię i budowę makrostrukturalną uzyskanych spoin.

\section{Abstract}

The article presents the results of experimental studies of welding conditions and compared the properties of butt-welding technology using innovative low energy variant of the MAG method - SpeedRoot in the PG position with a conventional TIG welding in the PF position. Rated capacity of both welding processes, the dynamic characteristics of power sources and the macrostructure of obtained joints.

\section{Wstęp}

Jedną z istotniejszych właściwości spawalniczych źródeł zasilania jest ich przydatność technologiczna określona zdolnością do zapłonu, a następnie stabilnego palenia się łuku, wielkością i ilością rozprysku metalu podczas spawania (dotyczy metod spawania opartych na elektrodzie topliwej) oraz elastycznością łuku. Przydatność ta jest wynikiem technologicznych właściwości źródeł spawalniczych określonych ich charakterystykami statycznymi i dynamicznymi.

Każda metoda spawania łukowego ma swoją specyfikę wynikającą z zakresu stosowanych parametrów, właściwości łuku (skład chemiczny przestrzeni łuko-

Dr inż. Marek Węglowski - RYWAL-RHC, dr inż. Tomasz Chmielewski - Politechnika Warszawska, dr inż. Krzysztof Kudła - Politechnika Częstochowska. wej, rodzaje elektrod itp.) oraz sposobów przechodzenia metalu w łuku, a tym samym stawia różne wymagania zasilaczom spawalniczym, zwłaszcza właściwościom dynamicznym.

Pod pojęciem stabilności procesu spawania rozumie się odporność źródła na różnego rodzaju zakłócenia wewnętrzne i/lub zewnętrzne, którym może ono ulegać w czasie spawania. Tak więc, badanie stabilności spawania najczęściej ogranicza się do uzyskania dobrej jakości spoiny, przy praktycznie niezmieniającej się na całej długości geometrii spoiny (szerokości, wysokości lica, głębokości wtopienia). Zgodnie

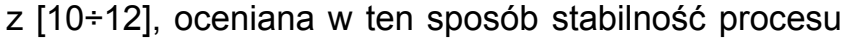
spawania jest stabilnością technologiczną. Rozwój nowych odmian metody MIG/MAG (SpeedUP, STT, CMT, AC Puls itp.) spowodował lepszą kontrolę nad ilością ciepła wprowadzaną do spoiny, poprawę jakości spoin, głębokości wtopienia oraz zwiększenie wydajności procesu spawania. Przedstawione w artykule wyniki badań dotyczą jedynie metody MAG w odmianie SpeedRoot w pozycji PG. 


\section{Badania eksperymentalne}

Proces spawania SpeedRoot jest nową odmianą metody MAG przeznaczoną do spawania warstw graniowych w spoinach czołowych również cienkich blach podczas łączenia we wszystkich pozycjach spawalniczych.

Celem prowadzonych badań było porównanie spawania w pozycji PG metodą SpeedRoot z metodą TIG w pozycji PF, pod względem podstawowych właściwości spoin oraz wydajności spawania. Badania wykonano częściowo w laboratorium Zakładu Inżynierii Spajania PW oraz w firmie Dantherm Filtration. Analizie poddano właściwości dynamiczne źródeł zasilania, w tym głównie rejestrowano przebiegi prądu spawania i napięcia łuku, które odnoszono do geometrii uzyskanych spoin. W ramach badań wykonano złącza doczołowe ze stali stopowej 1.4301. Do spawania metodą MAG-SpeedRoot zastosowano drut spawalniczy w gatunku G19 9LSi (wg PN-EN ISO 14343) marki MOST o średnicy $1 \mathrm{~mm}$, jako gazu osłonowego użyto mieszanki Cronigon S2 Grupa M13 (wg PN-EN ISO 14175:2008), natomiast w metodzie TIG zastosowano spoiwo o średnicy 1,2 mm G19 9LSi (wg PN-EN ISO 14343) marki MOST oraz argon jako gaz osłonowy (I1 wg PN-EN ISO 14175:2008).

Badanie wydajności spawania poszczególnych odmian metody MAG oraz TIG prowadzono w warunkach produkcyjnych, a uzyskane wyniki porównywano z uzyskaną wydajnością podczas spawania próbki wzorcowej wykonanej metodą TIG. Próby spawania wykonano ręcznie z zastosowaniem zbliżonych parametrów spawania (prąd spawania ok. 75 A). Do badań wytypowano urządzenia firmy LORCH: Saprom S (MAG SpeedRoot) oraz T220 (TIG).

$\mathrm{Na}$ podstawie uzyskanych wyników opracowano i wdrożono technologię spawania innowacyjnego filtra dla przemysłu spożywczego, wykonanego ze stali 1.4301. Filtr składał się z 4 podzespołów o długości $13 \mathrm{~m}$ każdy, mających po zmontowaniu łączną wysokość blisko $10 \mathrm{~m}$ i całkowitą masę ok. 18000 kg (rys. 3) tworząc 11 szczelnie oddzielonych sekcji, dostosowanych do pracy w warunkach ciśnienia dochodzącego do $7 \mathrm{kPa}$ i jednorazowo wytrzymujących eksplozję pyłu skutkującą chwilowym wzrostem ciśnienia do $20 \mathrm{kPa}$.

Przedmiotem prób było porównanie podstawowych właściwości spoin oraz wydajności spawania, jak również wdrożenie wybranej metody do produkcji przemysłowej.

Jedną z aplikacji metody SpeedRoot było jej wdrożenie w firmie Dantherm Filtration, która otrzymała zamówienie od klienta na zaprojektowanie i zbudowanie filtra do wychwytywania pyłu kawy z blachy 1.4301. Pył ten ma szczególnie dużą skłonność do zawieszania i tworzenia tzw. mostków. W związku z tą szczególnie kłopotliwą cechą pyłu kawy i ogólnymi wymaganiami dotyczącymi urządzeń dla przemysłu spożywczego, konieczne było całkowite przeprojektowanie filtra. Przy współpracy z Politechniką Warszawską i firmą
RYWAL-RHC, przyjęto koncepcję zastąpienia spoin pachwinowych przez spoiny czołowe, których lico następnie zeszlifowano i wypolerowano. Wstępnie zaplanowano spawanie spoin czołowych metodą TIG, jednak po wstępnej analizie podjęto wysiłek przeprowadzenia prób porównawczych metody TIG i innowacyjnej metody SpeedRoot.

$\mathrm{Na}$ potrzeby eksperymentu zaprojektowano, a następnie wykonano stanowisko badawcze (rys. 1 i 2). Jednocześnie opracowano i wdrożono technologię spawania blach $1.4301 \mathrm{w}$ złączach doczołowych w pozycjach PG i PF. Podczas badań obydwu metod zastosowano ręczne spawanie, które również stosowano w rzeczywistych warunkach prefabrykacji filtra.

Ocenę dynamicznych właściwości źródeł zasilania przeprowadzono na podstawie analizy zarejestrowanych czasowych przebiegów napięcia i prądu spawania.

Podczas badań wykonywano spoiny czołowe o długości ok. $1500 \mathrm{~mm}$. Parametry spawania przedstawiono w tablicy I. Do prób spawania wykorzystano próbki z blachy 1.4301 o długości $1500 \pm 5 \mathrm{~mm}$, szerokości $500 \pm 2 \mathrm{~mm}$ i grubości $2 \mathrm{~mm}$. Powierzchnia próbek była metalicznie czysta oraz wolna od zanieczyszczeń.

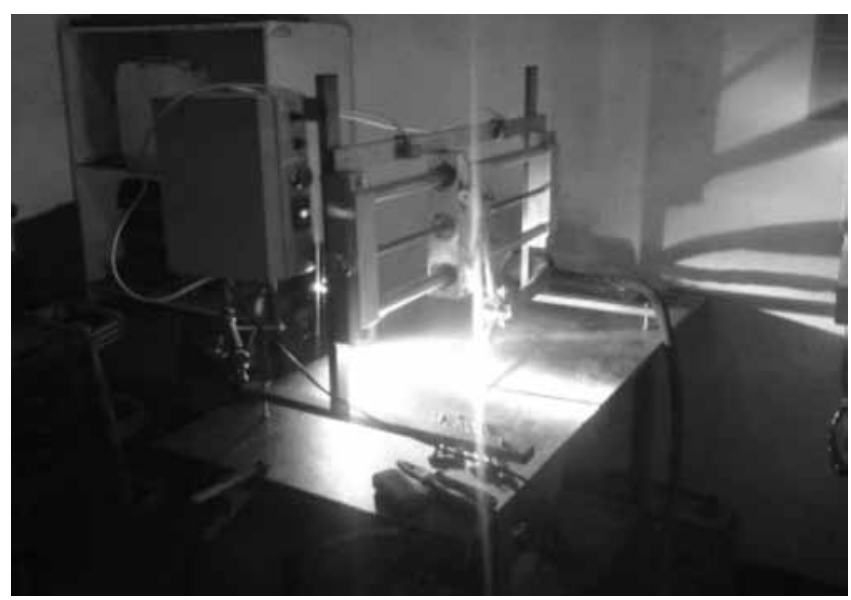

Rys. 1. Stanowisko badawcze zastosowane do badań porównawczych procesów TIG i Speed Root

Fig. 1. The comparable testing station for TIG and SpeedRoot process

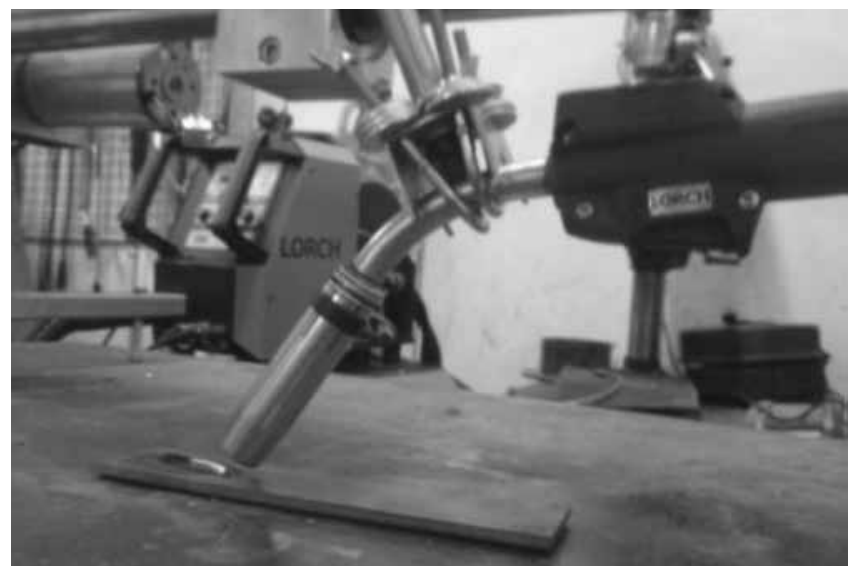

Rys. 2. Spawalnicze stanowisko badawcze z wykorzystaniem manipulatora postępowego podczas rejestracji przebiegów prądowo-czasowych

Fig. 2. Welding testing station with lineal manipulator during timecurrent characteristic recording 
Tablica I. Parametry spawania w pozycji przymusowej metodami TIG i SpeedRoot

Table I. TIG and SpeedRoot in the forced position welding process parameters

\begin{tabular}{|c|c|c|c|c|c|c|}
\hline Metoda & $\begin{array}{c}\text { Prąd spawania } \\
\text { A }\end{array}$ & $\begin{array}{c}\text { Napięcie łuku } \\
\text { V }\end{array}$ & $\begin{array}{c}\text { Prędkość posuwu drutu } \\
\mathrm{m} / \mathrm{min}\end{array}$ & $\begin{array}{c}\text { Prędkość spawania } \\
\mathrm{cm} / \mathrm{min}\end{array}$ & $\begin{array}{c}\text { Gaz osłonowy } \\
\text { I/min }\end{array}$ & $\begin{array}{c}\text { Pozycja } \\
\text { spawania }\end{array}$ \\
\hline TIG & 75 & 14 & - & 6,5 & 10, argon \\
\hline SpeedRoot & 75 & 16 & 3,5 & 30,0 & $10,98 \% \mathrm{Ar} / 2 \% \mathrm{O} 2$ & PG \\
\hline
\end{tabular}

Odniesieniem wydajności spawania dla ocenianych spoin była wykonana wcześniej spoina wzorcowa, standardową metodą TIG w pozycji PF. Podstawowym parametrem spawania porównywalnym dla wszystkich przypadków był prąd spawania o wartości ok. 75 A (tabl. I). Pozostałe parametry w metodzie SpeedRoot dobierano automatycznie przez system synergicznego sterowania urządzenia spawalniczego. Prędkość spawania dobierano w taki sposób, aby nominalna grubość spoiny była zbliżona do spoiny próbki wzorcowej z pełnym przetopem. W tablicy II przedstawiono zarejestrowane przebiegi dynamiczne prądowo-czasowe oraz makrostruktury przekroju poprzecznego spoin.

Z przprowadzonych eksperymentów wynika, że w obu metodach uzyskano prawidłowe złącza. W procesie TIG szerokość spoiny oraz SWC były większe niż przy zastosowaniu metody SpeedRoot. Wynika to z większych prędkości spawania $w$ metodzie SpeedRoot niż w metodzie TIG. Odkształcenia spoin wykonanych metodą SpeedRoot spowodowane naprężeniami własnymi również były zdecydowanie mniejsze niż w metodzie TIG.

Po przedstawieniu wstępnych wyników badań firmie Dantherm Filtration podjęto decyzję o wdrożeniu metody SpeedRoot do produkcji i wykonanie prób już na budowanym filtrze. Próby w warunkach przemysłowych również dały pozytywny wynik. Wydajność spawania metodą SpeedRoot była pięciokrotnie większa niż TIG, dodatkowym walorem było znaczne ograniczenie odkształceń spawalniczych, które są trudne do kontrolowania w przypadku cienkościennych konstrukcji wielkogabarytowych (rys. 3 i 4). Duże znaczenie na decyzję inwestora o wdrożeniu miała również innowacyjność niskoenergetycznego procesu MAG SpeedRoot-LORCH. Nowa odmiana metody MAG jest oparta na znanym od lat 80 . XX w. procesie przechodzenia kropli przy udziale sił pochodzących od napięcia powierzchniowego. Urządzenia starsze bazowały na tzw. hardware, co podnosiło znacznie cenę w stosunku

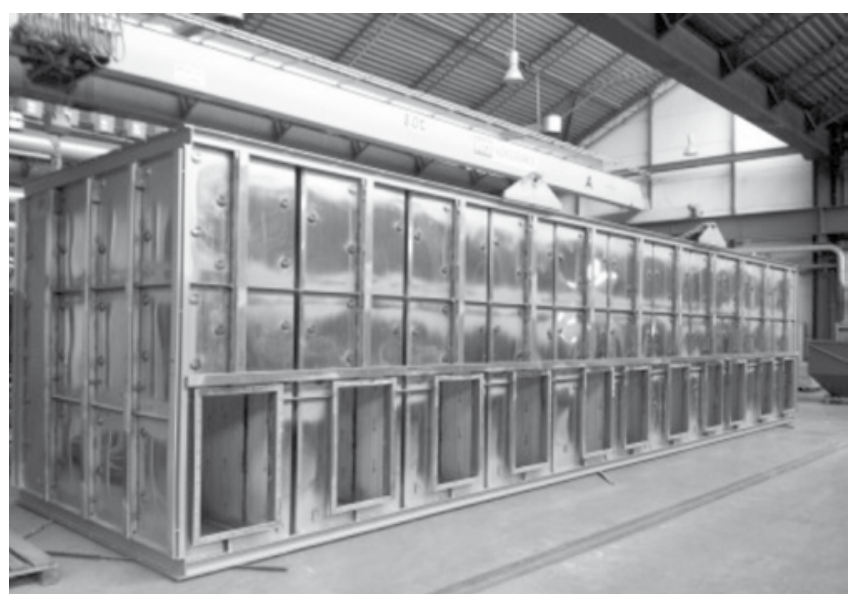

Rys. 3. Część filtra wykonanego metodą SpeedRoot

Fig. 3. A part of filter made using SpeedRoot method

Tablica II. Charakterystyki dynamiczne oraz makrostruktury spoin wykonanych metodami TIG i SpeedRoot Table II. Dynamic characteristics and macrostructures of joint made using TIG and SpeedRoot method

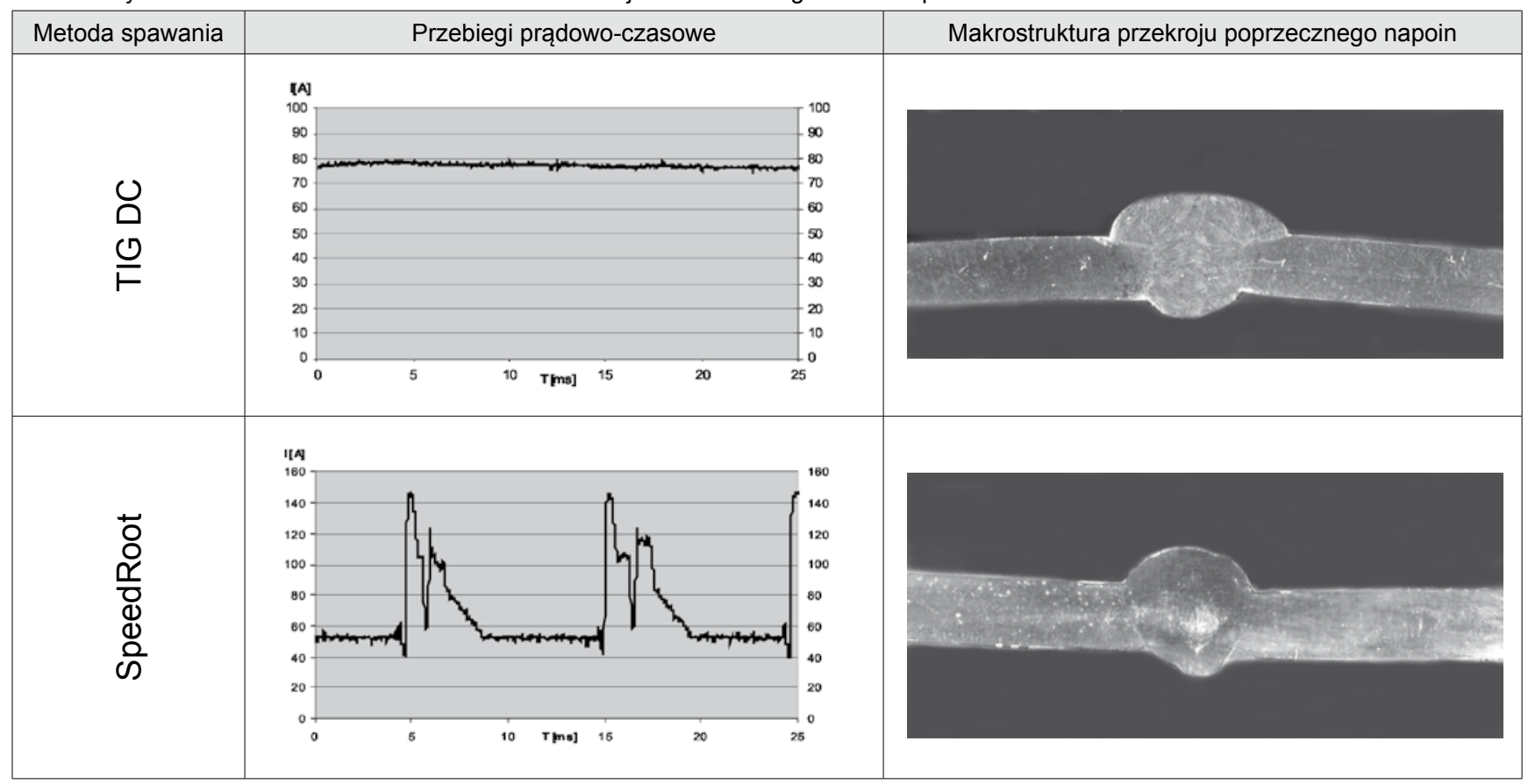




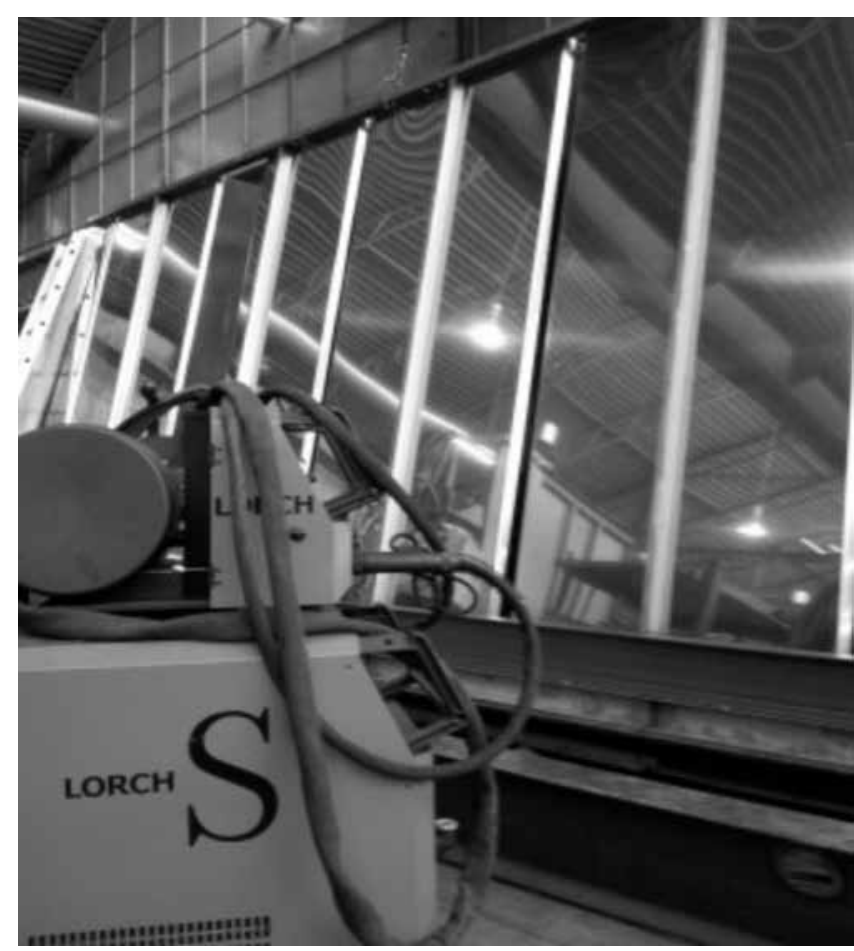

Rys. 4. Zasadnicza część filtra podczas montażu przy zastosowaniu metody SpeedRoot

Fig. 4. The main part of filter in the montage process with the use of SpeedRoot method

do urządzeń MAG Standard, przez co ograniczało ich dostępność. Konstruktorzy firmy LORCH zastosowali inne podejście, tzw. software'owe na którym oparta jest opracowana metoda SpeedRoot. Oprócz programu sterującego zaprojektowano funkcje synergiczne, dzięki którym po wprowadzeniu do urządzenia takich danych jak rodzaj drutu spawalniczego, jego średnica oraz rodzaj gazu osłonowego, dobierane są parametry spawania za pomocą jednego regulatora pokrętłem, ustawiając jedynie prąd spawania. Reszta parametrów takich jak napięcie łuku, posuw drutu elektrodowego i inne wielkości opisowe dobierane są synergicznie przez system sterowania urządzenia.

W procesie SpeedRoot po zwarciu drutu elektrodowego $z$ materiałem spawanym prąd spawania gwałtownie rośnie do momentu utworzenia minimalnego przewężenia ciekłego metalu (łączącego koniec elektrody z jeziorkiem spawalniczym). Zerwanie mostka i transport kropli następuje na skutek działania sił pochodzących od napięcia powierzchniowego już przy niskim prądzie, co skutkuje bezrozpryskowym przejściem metalu, jak w klasycznym procesie MAG Standard. Kolejny w cyklu pik prądu powoduje rozgrzanie końcówki drutu elektrodowego, który tworzy stosunkowo dużą kroplę, tak aby przy następnym cyklu jak najwięcej materiału dodatkowego przeszło do spoiny, przy jednocześnie niskim jego utlenieniu i naazotowaniu.

W badanych urządzeniach do spawania metodą SpeedRoot zastosowano wiele nowoczesnych rozwiązań. Jedną z ważniejszych cech tego typu urządzeń jest duża częstotliwość taktowania procesorów, które pozwalają prawidłowo i szybko reagować układowi sterowania i regulacji. Układy te na bieżąco sprawdzają warunki procesu spawania i odpowiednio reagują na np. wydłużający się czas zwarcia lub zmianę długości łuku spawalniczego, aby zachować stabilne przechodzenie materiału do spoiny. Dzięki temu przy wystapieniu różnego typu zakłóceń urządzenie szybko reaguje ograniczając ryzyko powstawania niezgodności spawalniczych. Dodatkową zaletą metody SpeedRoot w porównaniu do rozwiązań z lat 90 . jest to, iż na tej samej konstrukcji może pracować jednocześnie kilka źródeł prądu bez wzajemnego zakłócania się, jak to ma miejsce podczas spawania innymi niskoenergetycznymi odmianami MAG bazującymi na dodatkowym pomiarze napięcia. Wymieniona cecha była jednym z ważniejszych czynników branych pod uwagę $w$ firmie Dantherm Filtration, aby była możliwość zastosowania kilku stanowisk na jednym odcinku wzajemnie nie zakłócających się.

Zastosowane w ramach badań urządzenie Saprom S firmy LORCH jest uniwersalnym źródłem energii spawania dla różnych odmian metody MAG. Oprócz oprogramowania SpeedRoot specjalizowanego do spawania jednościegowych spoin pionowych, warstw graniowych i przetopów, może być jednocześnie stosowane oprogramowanie SpeedUp do wykonywania wypełnienia w pozycji pioniowej PF i inne jak MAG Standard, SpeedPulse, SpeedArc - te dwie ostatnie dają możliwość spawania drutem pełnym $z$ dużo większymi prędkościami spawania niż w klasycznym MAG Standard oraz bezrozpryskowo.

\section{Podsumowanie}

W pracy przedstawiono wyniki analizy i porównania podstawowych właściwości wybranych spawalniczych źródeł energii elektrycznej z wewnętrzną przemianą częstotliwości. Badano jedno z nowszych urządzeń do spawania łukowego o zewnętrznych napięciowych charakterystykach statycznych. Wyniki badań posłużyły do wdrożenia nowej metody spawania SpeedRoot w procesie produkcyjnym. Zastosowanie tej metody umożliwiło uzyskanie blisko pięciokrotnie większej wydajności spawania niż w porównywanym procesie spawania TIG. Uzyskano złącza wolne od rozprysków oraz o prawidłowym przetopie, przy ograniczonej deformacji złącza spawanego.

Metoda ta jest również wprowadzana do przemysłu związanego z obróbką rur, gdzie jednym urządzeniem wykonuje się warstwę przetopową graniową metodą SpeedRoot, a następnie tym samym urządzeniem po przełączeniu na inną funkcje robi się wypełnienie np. drutami pełnymi lub proszkowymi. 


\section{Literatura}

[1] Kolasa A.: Właściwości dynamiczne źródeł energii elektrycznej do spawania łukowego oraz kryteria ich oceny, Prace Naukowe Politechniki Warszawskiej, Warszawa 1990.

[2] Pakos R.: Ocena stabilności procesu napawania metodą MAG drutem pełnym i proszkowym, Przegląd Spawalnictwa nr 9-10/2003.

[3] Dobaj E.: Maszyny i urządzenia spawalnicze, Wydawnictwa Naukowo-Techniczne, Warszawa, 1998.

[4] Kang M. J., Kim Y., Ahn S., Rhee S.: Spatter Rate Estimation in the Short-Circuit Transfer Region of GMAW, Welding Journal no. September 2003.

[5] Słania J.: Badania półautomatów do spawania metodą MIG/ MAG prowadzone w Laboratorium Badawczym Spawalnictwa, Biuletyn Instytutu Spawalnictwa nr 2/1995.

[6] Lucas B., Melton E. I. G.: Let's get technical - choosing an arc welding power source, Welding \& Metal Fabrication, May 1999.

[7] Kang Y.H., Na S.J.: A Study on Modeling of Magnetic Arc Deflection and Dynamic Analysis of Arc Sensor, Welding Journal no. January 2002.

[8] Kensik R.: Eksploatacja urządzeń spawalniczych, Część I Źródła spawalnicze, Wydawnictwo Politechniki Częstochowskiej, Częstochowa 1995.
[9] Węglowski M., Kolasa A., Cegielski P.: Ocena stabilności procesu ręcznego spawania łukowego elektrodami otulonymi, Przegląd Spawalnictwa, nr 1/2006.

[10] Węglowski M.: Badania właściwości spawalniczych źródeł energii elektrycznej z wewnętrzną przemianą częstotliwości, Rozprawa doktorska, Warszawa 2008.

[11] Węglowski M., Chmielewski T., Kudła K.: Porównanie wybranych właściwości nowoczesnych spawalniczych inwertorowych źródeł energii przeznaczonych do spawania metodą MAG, 51 Naukowo-Techniczna Konferencja Spawalnicza, Dębe 22-24.10.2009.

[12] Węglowski M., Chmielewski T.: Badania właściwości urzadzeń z wewnętrzną przemianą częstotliwości przeznaczonych do spawania metoda MAG, XVII Międzynarodowa Konferencja Spawalnicza Energetyków, Opole - Turawa, 20-23 kwietnia 2010.

[13] Węglowski M., Chmielewski T.: Efektywność spawania w odmianach metody MAG na podstawie wybranych właściwości spawalniczych, I Konferencja Polskiej Izby Producentów Urządzeń i Usług „Nowoczesne Technologie Obróbki Metali”, Bydgoszcz, 31 marca - 1 kwietnia 2011.

[14] Katalog RYWAL-RHC, Wydanie trzecie, Toruń 2011.

\section{\$\& 4METAL.PL}

\section{Ponad 2000 podwykonawców z całego świata}

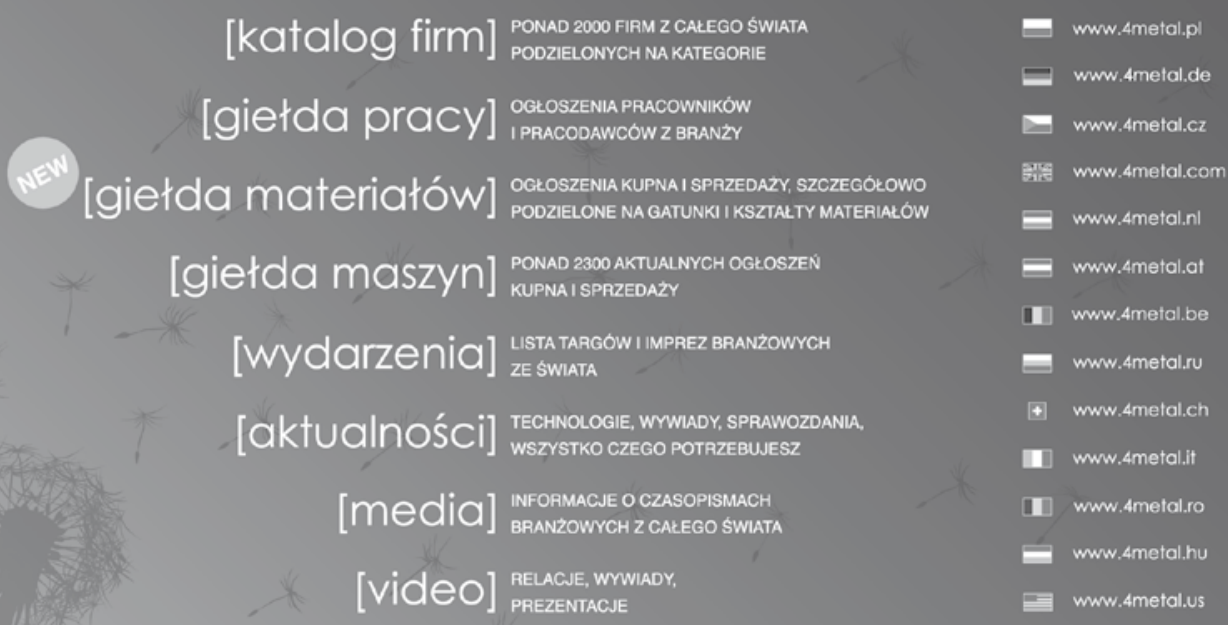

